\title{
Chronic Kidney Disease and the Risk of End-Stage Renal Disease versus Death
}

\author{
Lorien S. Dalrymple, MD, MPH' ${ }^{7}$ Ronit Katz, DPhil ${ }^{2}$, Bryan Kestenbaum, MD, $M S^{3}$, \\ Michael G. Shlipak, MD, MPH ${ }^{4,5}$, Mark J. Sarnak, MD, MS ${ }^{6}$, Catherine Stehman-Breen, MD, MS ${ }^{7}$, \\ Stephen Seliger, $M D, M S^{8}$, David Siscovick, MD, MPH ${ }^{3,9}$, Anne B. Newman, MD, MPH ${ }^{10,11}$, \\ and Linda Fried, MD, MPH ${ }^{10,11,12}$
}

\begin{abstract}
'Department of Medicine, University of California Davis, Sacramento, CA, USA; ${ }^{2}$ Department of Biostatistics, University of Washington, Seattle, WA, USA; ${ }^{3}$ Department of Medicine, University of Washington, Seattle, WA, USA; ${ }^{4}$ General Internal Medicine Section, Medical Service, Veterans Affairs Medical Center, San Francisco, CA, USA; ${ }^{5}$ Department of Medicine, University of California, San Francisco, CA, USA; ${ }^{6}$ Department of Medicine, Tufts Medical Center, Boston, MA, USA; ${ }^{7}$ Amgen Inc., Thousand Oaks, CA, USA; ${ }^{8}$ Department of Medicine, University of Maryland School of Medicine, Baltimore, MD, USA; ${ }^{9}$ Department of Epidemiology, University of Washington, Seattle, WA, USA; ${ }^{10}$ Department of Medicine, University of Pittsburgh School of Medicine, Pittsburgh, PA, USA; " Department of Epidemiology, University of Pittsburgh School of Medicine, Pittsburgh, PA, USA; ${ }^{12}$ Renal Section, VA Pittsburgh Health Care System, Pittsburgh, PA, USA.
\end{abstract}

BACKGROUND: Among older adults with chronic kidney disease (CKD), the comparative event rates of endstage renal disease (ESRD) and cause-specific death are unknown.

OBJECTIVE: To compare the rates of ESRD, cardiovascular and non-cardiovascular death and examine risk factors for ESRD and all-cause mortality in Cardiovascular Health Study (CHS) participants.

DESIGN: The CHS is a longitudinal cohort study of community-dwelling adults aged 65 years and older.

PARTICIPANTS: 1,268 participants with an estimated glomerular filtration rate $(\mathrm{eGFR})<60 \mathrm{ml} / \mathrm{min}$ per $1.73 \mathrm{~m}^{2}$ were followed until the time of first event (ESRD, cardiovascular or non-cardiovascular death) or until March 31, 2003.

MAIN MEASURES: The outcomes were ESRD, cardiovascular- and non-cardiovascular death. Rates of each event were calculated, and a Cox Proportional Hazards Model with a competing risk framework was used to examine risk factors for ESRD as compared with death. Predictors included age, gender, race, BMI, hypertension, diabetes, cardiovascular disease, heart failure, tobacco use, eGFR, and total cholesterol.

KEY RESULTS: During 9.7 years of follow-up, 5\% of the cohort progressed to ESRD, and $61 \%$ of the cohort died. The rate (per 100 person-years) was 0.5 for ESRD and 6.8 for all-cause mortality (3.0 for cardiovascular and 3.8 for non-cardiovascular mortality). In the competing risk framework, lower eGFR, male gender, African-American race, and higher BMI were associated with an increased risk of ESRD.

CONCLUSIONS: Older adults with CKD are 13-fold more likely to die from any cause than progress to ESRD and are 6-fold more likely to die from cardiovascular causes than develop ESRD.

Received April 15, 2010

Revised August 17, 2010

Accepted August 26, 2010

Published online September 19, 2010
KEY WORDS: renal disease; cardiovascular disease; clinical epidemiology. J Gen Intern Med 26(4):379-85

DOI: $10.1007 / \mathrm{s} 11606-010-1511-\mathrm{x}$

(C) The Author(s) 2010. This article is published with open access at Springerlink.com

\section{INTRODUCTION}

In the United States, approximately one in three adults aged 65 years and older has chronic kidney disease (CKD), defined as an eGFR $<60 \mathrm{ml} / \mathrm{min} / 1.73 \mathrm{~m}^{2}$. ${ }^{1}$ The majority of patients with CKD do not progress to advanced stages of CKD because death precedes the progression to end-stage renal disease (ESRD), ${ }^{2-4}$ even among patients with stage $4 \mathrm{CKD} .^{2}$ The risk of death as compared to the risk of progression to ESRD may be even higher in older patients with established CKD. To date, studies have not specifically examined the comparative event rates of kidney disease progression and death and determined cause-specific death in older adults with established CKD. Given the aging population, ${ }^{5}$ the increasing prevalence of $\mathrm{CKD},{ }^{6}$ and the association of CKD with mortality, ${ }^{7-9}$ understanding the clinical course and outcomes of older patients with CKD is particularly important. For these reasons, we examined the rates of ESRD, cardiovascular death (CV death), and non-cardiovascular death (non-CV death) among older, community-dwelling adults with moderate $\mathrm{CKD}$, and we determined the risk factors for progression from CKD to ESRD and to death within a competing mortality risk framework.

\section{METHODS}

Participants. The Cardiovascular Heath Study (CHS) is a prospective cohort study of community-dwelling persons 65 years of age and older designed to examine the epidemiology 
of cardiovascular disease in older adults. ${ }^{10}$ Between 1989 and 1990, the CHS recruited 5,201 Medicare-eligible participants from Forsyth County, NC; Sacramento County, CA; Washington County, MD; and Pittsburgh, PA. ${ }^{11}$ Between 1992 and 1993, the study recruited an additional 687 African-American participants. CHS exclusion criteria included: institutionalization, inability to provide informed consent, intention to move outside the enrollment area within 3 years, use of a wheelchair within the home, hospice care, or current chemotherapy or radiation for cancer. At the time of study entry, extensive clinical data were collected, including demographics, comorbid conditions, biochemical data, and prevalent cardiovascular risk factors. Participants were followed prospectively for cardiovascular events (coronary artery disease, angina, congestive heart failure, stroke, claudication), hospitalizations, and death by contact every 6 months. ${ }^{12,13}$

To focus on the competing risks of death versus progression of chronic kidney disease, we selected only those CHS participants with a Modification of Diet in Renal Disease estimated glomerular filtration rate (MDRD eGFR) $<60 \mathrm{ml} / \mathrm{min}$ per $1.73 \mathrm{~m}^{2}$ at baseline. We further excluded participants if they had no baseline serum creatinine measurement, prevalent ESRD requiring dialysis therapy, or the cause of death could not be determined.

Outcomes. The primary outcomes of interest were ESRD (defined as renal failure requiring renal replacement therapy) and death; CV and non-CV death were secondary outcomes of interest. To ascertain ESRD, the CHS cohort was linked to the United States Renal Data System (USRDS) in 2005 (which included data through March 31, 2003). In addition, a chart review was performed to determine which CHS participants met criteria for ESRD yet elected not to initiate dialysis, died prior to receiving dialysis, or died prior to being enrolled in the USRDS (e.g., initiated dialysis in the hospital and subsequently withdrew dialysis). To identify these potential CHS participants with ESRD who were not included in the USRDS, charts of CHS participants were reviewed if the participant had a procedure code for dialysis, discharge diagnoses suggesting ESRD (e.g., renal failure, ESRD, dialysis, or renal transplant), or the cause of death was renal failure or failure to thrive. The charts were reviewed by one investigator (LF), and potential cases were reviewed by the CHS renal working group for concurrence.

$\mathrm{CV}$ death was defined as death due to cardiovascular, cerebrovascular, atherosclerotic, or other vascular causes, and was adjudicated by the CHS Events Subcommittee by a protocol previously described in detail, ${ }^{12}$ any death other than those mentioned above was considered to be a non-CV death (e.g., cancer, dementia, pulmonary disease, or infection). In the CHS study, death was determined by examining the Social Security Death Index, Medicare claims data, local obituaries, and proxy report. The cause of death was adjudicated by committee and was based on review of medical records, death certificates, autopsy reports, and descriptions by the proxy. ${ }^{12,14}$ Participants were followed until the time of a first event or until March 31, 2003, whichever came first.

\section{Clinical Assessment and Measurement}

All methods employed to asses the baseline characteristics of the CHS cohort have been described elsewhere. ${ }^{10,13,15}$ Demo- graphic factors (age, gender, race), health behaviors (smoking), co-existing illnesses (diabetes and hypertension), physical exam findings (body mass index, systolic and diastolic blood pressure), and laboratory values (total cholesterol, creatinine and glucose) were ascertained at study entry. Diabetes was defined by the use of a medication for diabetes or fasting glucose level $\geq 126 \mathrm{mg} / \mathrm{dl}$. Hypertension was defined by systolic pressure $\geq 140 \mathrm{mmHg}$, diastolic pressure $\geq 90 \mathrm{~mm} \mathrm{Hg}$, or the use of antihypertensive medication(s). Prevalent coronary heart disease (CHD) and prevalent congestive heart failure (CHF) were defined using participant self-report, medical record review, findings from the baseline physical examination, and physician questionnaires. ${ }^{13}$ Smoking was classified as never, former, or current. Serum creatinine levels were measured using the Kodak Ektachem 700 Analyzer (Eastman Kodak, Rochester, New York), a colorimetric method. Serum creatinine was calibrated to the Cleveland Clinic Laboratory using indirect calibration to the NHANES III data. ${ }^{16}$ Creatininebased estimated GFR was calculated using the four-variable Modification of Diet in Renal Disease (MDRD) equation, eGFR = $186.3 \mathrm{X}$ (serum creatinine ${ }^{-1.154}$ ) $\mathrm{x}\left(\right.$ age $\left.^{-0.203}\right) \times 1.212$ (if black) X 0.742 (if female). ${ }^{17}$

\section{Statistical Analyses}

Baseline characteristics by categories of MDRD eGFR (eGFR 45 to $<60$ or $<45 \mathrm{ml} / \mathrm{min}$ per $1.73 \mathrm{~m}^{2}$ ) were described as means, medians, or proportions. Unadjusted incidence rates for progression to ESRD and all-cause mortality (further categorized as CV or non-CV related) were calculated per 100 person-years and also described with respect to eGFR categories. A standard Cox proportional hazards model analysis was not felt to be adequate in the presence of competing risks because the cause-specific Cox model treats competing risks of the event of interest as censored observations, and the cause-specific hazard function does not have a direct interpretation in terms of survival probability. Therefore, a competing risk model was used to examine risk factors for ESRD as compared with all-cause mortality. The variables included in the competing risk model were age, gender, race, BMI $(<18.5,18.5-24.9,25-29.9$, or $\geq 30)$, hypertension, diabetes, cardiovascular disease, heart failure, tobacco use (never, former, or current), eGFR, and total cholesterol (<200, 200-239, or $\geq 240 \mathrm{mg} / \mathrm{dl}$ ). These variables were selected for inclusion in the analysis because of their potential association with the risk of ESRD and/or death and their availability in usual clinical practice (thereby allowing for inference by clinicians). First, we computed the cumulative incidence function (CIF) of ESRD over time. At time $t$, the CIF defined the probability of having ESRD by time $t$ while other participants had experienced a death (CV or non-CV). We used the method proposed by Fine and Gray, which is based on the proportional hazards model and models directly the effect of covariates on the $\mathrm{CIF}$ for competing risk data. ${ }^{18}$ Our model distinguished between participants who were still alive and those who had already failed from competing causes and allowed for direct inference regarding the effects of covariates on the CIF. The cumulative incidence of ESRD in the presence of $\mathrm{CV}$ and non-CV mortality as competing risks was calculated similarly to the Kaplan-Meier method, except in the competing risk method participants who died were counted as events when calculating the event-free survival and only participants who were truly alive 
were considered at risk for ESRD. Similarly, the cumulative incidences of CV and non-CV mortality in the presence of ESRD as a competing risk were calculated. All analyses were performed using R 2.9.1 software (R Foundation for Statistical Computing http://www.R-project.org) and SPSS statistical software (release 15.0.1.1, Chicago, IL).

Investigational Review Board approval for the data collection procedures of CHS was obtained at each of the four clinical sites and at the Data Coordinating Center (University of Washington).

\section{RESULTS}

CHS enrolled 5,888 participants, ${ }^{11}$ and after exclusions, a total of 1,268 subjects were included in the present study (Fig. 1). The mean age of the cohort was 75 years, $46 \%$ of the cohort was male, and the mean and median eGFR at study entry were 51 and $53 \mathrm{ml} / \mathrm{min}$ per $1.73 \mathrm{~m}^{2}$, respectively. At study entry $77.7 \%$ of the cohort had stage 3a CKD (eGFR $45-59 \mathrm{ml} / \mathrm{min}$ per $1.73 \mathrm{~m}^{2}$ ), $18.3 \%$ had stage 3b CKD (eGFR $30-44 \mathrm{ml} / \mathrm{min}$ per $1.73 \mathrm{~m}^{2}$ ), 3.4\% had stage 4 CKD (eGFR 15$29 \mathrm{ml} / \mathrm{min}$ per $1.73 \mathrm{~m}^{2}$ ), and $0.6 \%$ had stage $5 \mathrm{CKD}$ not requiring dialysis (eGFR $<15 \mathrm{ml} / \mathrm{min} / 1.73 \mathrm{~m}^{2}$ ). Among the participants, $33 \%$ had prevalent cardiovascular disease, $17 \%$ had prevalent diabetes, and 69\% had prevalent hypertension (Table 1). The mean and median follow-up times were 8.9 and 9.7 years, respectively.

During follow-up there were a total of 768 deaths $(61 \%$ of cohort); of these, 338 were due to cardiovascular causes (44\%), and 430 (56\%) were due to non-cardiovascular causes. Sixty participants $(4.7 \%)$ progressed to ESRD. Figure 2 shows the cumulative incidence of events with consideration of the competing risk. Of the 60 participants with ESRD, 50 were identified through linkage to USRDS,

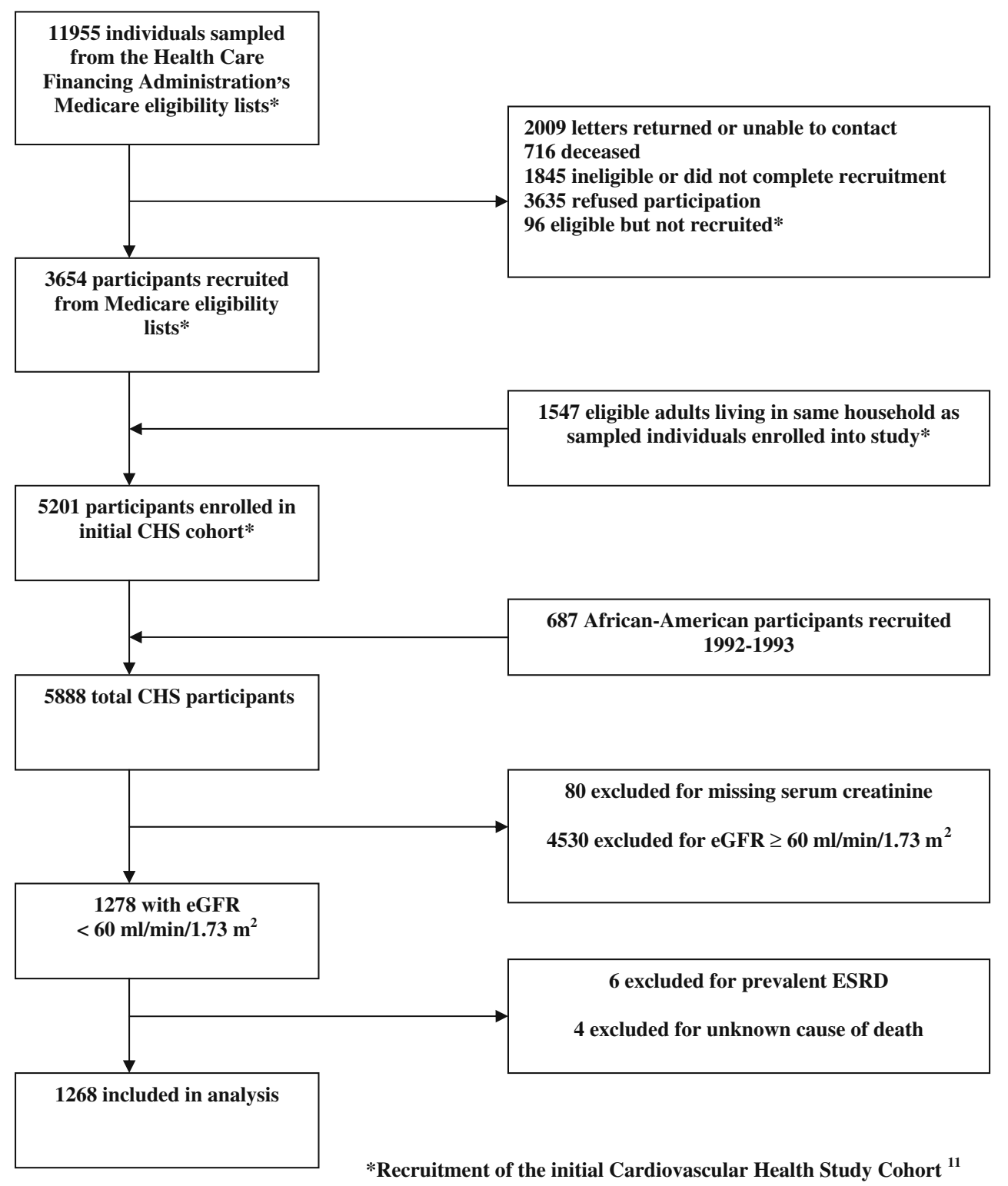

Figure 1. Recruitment of Cardiovascular Health Study participants and selection of chronic kidney disease cohort. 
Table 1. Baseline Participant Characteristics

\begin{tabular}{|c|c|c|c|}
\hline & eGFR $<60 \mathrm{ml} / \mathrm{min} / 1.73 \mathrm{~m}^{2} \mathrm{n}=1,268$ & eGFR 45 to $<60 \mathrm{ml} / \mathrm{min} / 1.73 \mathrm{~m}^{2} \mathrm{n}=985$ & eGFR $<45 \mathrm{ml} / \mathrm{min} / 1.73 \mathrm{~m}^{2} \mathrm{n}=283$ \\
\hline $\operatorname{MDRD} \operatorname{eGFR}^{a}\left(\mathrm{ml} / \mathrm{min} / 1.73 \mathrm{~m}^{2}\right)$ & $51 \pm 9$ & $55 \pm 4$ & $36 \pm 8$ \\
\hline Age (years) & $75 \pm 6$ & $74 \pm 6$ & $77 \pm 7$ \\
\hline Male & $580(46 \%)$ & 440 (45\%) & 140 (50\%) \\
\hline African-American & 140 (11\%) & $97(10 \%)$ & $43(15 \%)$ \\
\hline Body mass index $\left(\mathrm{kg} / \mathrm{m}^{2}\right)$ & $26.7 \pm 4.6$ & $26.7 \pm 4.6$ & $26.5 \pm 4.7$ \\
\hline Diabetes & $217(17 \%)$ & 157 (16\%) & $60(21 \%)$ \\
\hline Hypertension & $877(69 \%)$ & $656(67 \%)$ & $221(78 \%)$ \\
\hline Prevalent cardiovascular disease & $414(33 \%)$ & $297(30 \%)$ & $117(41 \%)$ \\
\hline Prevalent heart failure & $104(8 \%)$ & $64(7 \%)$ & $40(14 \%)$ \\
\hline Systolic blood pressure (mmHg) & $139 \pm 23$ & $138 \pm 23$ & $143 \pm 25$ \\
\hline Diastolic blood pressure (mmHg) & $71 \pm 12$ & $71 \pm 12$ & $71 \pm 13$ \\
\hline Antihypertensive medications & $792(63 \%)$ & 579 (59\%) & $213(75 \%)$ \\
\hline $\mathrm{ACEI}^{b}$ & $149(12 \%)$ & $102(10 \%)$ & $47(17 \%)$ \\
\hline \multicolumn{4}{|l|}{ Smoking status } \\
\hline Former & $537(42 \%)$ & 425 (43\%) & $112(40 \%)$ \\
\hline Current & $128(10 \%)$ & $94(10 \%)$ & $34(12 \%)$ \\
\hline Total cholesterol (mg/dl) & $212 \pm 42$ & $212 \pm 41$ & $212 \pm 46$ \\
\hline Low density lipoprotein (mg/dl) & $131 \pm 38$ & $131 \pm 37$ & $132 \pm 42$ \\
\hline High density lipoprotein (mg/dl) & $51 \pm 15$ & $52 \pm 15$ & $49 \pm 16$ \\
\hline
\end{tabular}

Data are presented as mean $\pm \mathrm{SD}$ or number (\%) of subjects; ${ }^{a}$ Modification of Diet in Renal Disease estimated glomerular filtration rate; ${ }^{b}$ angiotensinconverting enzyme inhibitor

and a further 10 were identified through chart review. Overall, the rates per 100 person-years were 0.5 for ESRD and 6.8 for allcause mortality ( 3.0 for $\mathrm{CV}$ and 3.8 for non-CV mortality). The rates of events were notably higher in those participants with an eGFR $<45 \mathrm{ml} / \mathrm{min}$ per $1.73 \mathrm{~m}^{2}$ and in participants over 85 years of age (Table 2).

In the multivariate Cox proportional hazards model with a competing risk framework, factors associated with an increased risk of progression to ESRD included male gender, AfricanAmerican race, a $\mathrm{BMI} \geq 25$ (as compared with a BMI of 18.524.9), and lower eGFR. In comparison, older age, male gender, a $\mathrm{BMI}<18.5$ (compared with a BMI of 18.5-24.9), hypertension, diabetes, cardiovascular disease, heart failure, and former and current tobacco use were each associated with an increased risk of all-cause mortality (Table 3).

\section{DISCUSSION}

In our study of community-dwelling older persons with CKD, we found participants were 13-fold more likely to die from any cause than to progress to ESRD and 6-fold more likely to die from cardiovascular-related causes. Among participants 76 to 85 years of age, the risk of death was more than 25-fold higher than the risk of ESRD. Even among participants with more advanced CKD (eGFR $<45 \mathrm{ml} / \mathrm{min}$ per $\left.1.73 \mathrm{~m}^{2}\right)$, death from

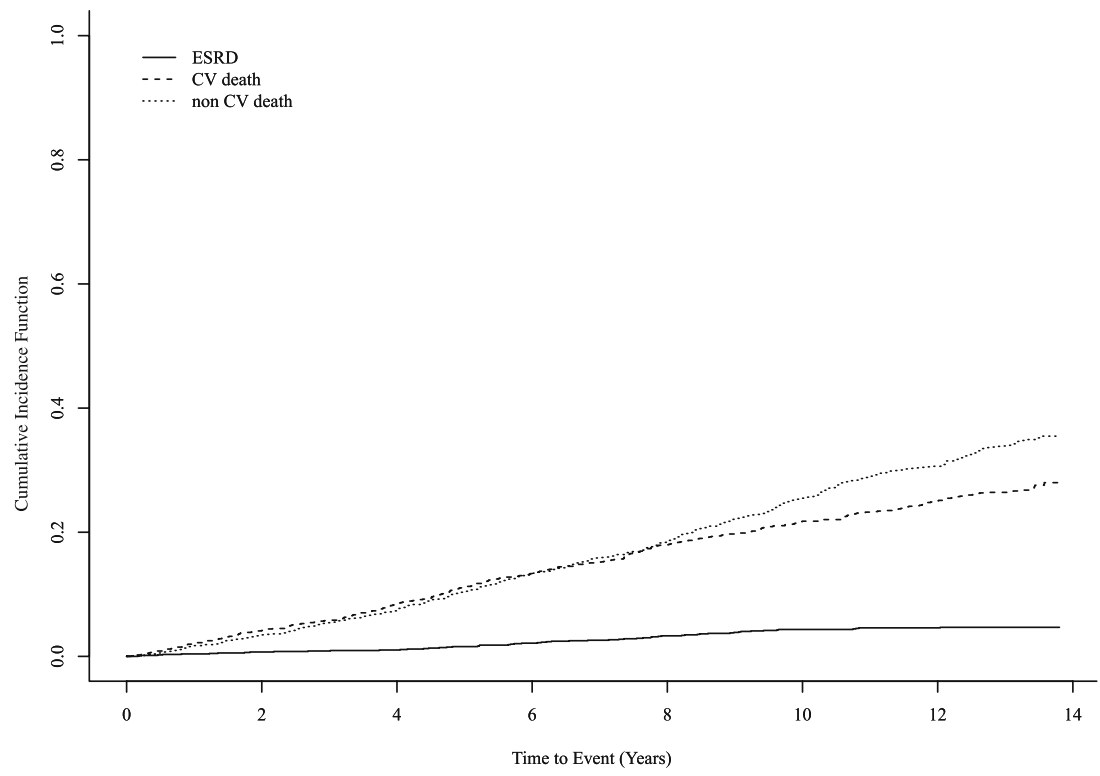

Figure 2. The cumulative incidence of end-stage renal disease (ESRD), cardiovascular death, and non-cardiovascular death during follow-up. 
Table 2. Rates of End-Stage Renal Disease, All-Cause, Cardiovascular and Non-Cardiovascular Mortality

\begin{tabular}{|c|c|c|c|c|c|c|c|c|c|}
\hline & \multirow[t]{2}{*}{$\mathbf{N}$} & \multicolumn{2}{|c|}{$\begin{array}{l}\text { End-stage renal } \\
\text { disease }\end{array}$} & \multicolumn{2}{|c|}{$\begin{array}{l}\text { All-cause } \\
\text { mortality }\end{array}$} & \multicolumn{2}{|c|}{$\begin{array}{l}\text { Cardiovascular } \\
\text { mortality }\end{array}$} & \multicolumn{2}{|c|}{$\begin{array}{l}\text { Non- } \\
\text { cardiovascular mortality }\end{array}$} \\
\hline & & Events & $\begin{array}{l}\text { Rate per } 100 \\
\text { person-years } \\
(95 \% \mathrm{Cl})\end{array}$ & Events & $\begin{array}{l}\text { Rate per } 100 \\
\text { person-years } \\
(95 \% \mathrm{Cl})\end{array}$ & Events & $\begin{array}{l}\text { Rate per } 100 \\
\text { person-years } \\
(95 \% \mathrm{Cl})\end{array}$ & Events & $\begin{array}{l}\text { Rate per } 100 \\
\text { person-years } \\
(95 \% \mathrm{Cl})\end{array}$ \\
\hline \multicolumn{10}{|c|}{ MDRD eGFR $^{a}$} \\
\hline$<60$ & 1,268 & 60 & $0.5(0.4,0.7)$ & 768 & $6.8(6.4,7.3)$ & 338 & $3.0(2.7,3.3)$ & 430 & $3.8(3.5,4.2)$ \\
\hline 45 to $<60$ & 985 & 26 & $0.3(0.2,0.4)$ & 570 & $6.1(5.6,6.6)$ & 245 & $2.6(2.3,3.0)$ & 325 & $3.5(3.1,3.9)$ \\
\hline$<45$ & 283 & 34 & $1.8(1.2,2.4)$ & 198 & $10.3(8.8,11.7)$ & 93 & $4.8(3.8,5.8)$ & 105 & $5.4(4.4,6.5)$ \\
\hline \multicolumn{10}{|l|}{ Age (years) } \\
\hline $65-75$ & 745 & 41 & $0.5(0.4,0.7)$ & 355 & $4.8(4.3,5.3)$ & 150 & $2.0(1.7,2.3)$ & 205 & $2.8(2.4,3.1)$ \\
\hline $76-85$ & 449 & 15 & $0.4(0.2,0.7)$ & 346 & $10.2(9.1,11.3)$ & 150 & $4.4(3.7,5.1)$ & 196 & $5.8(5.0,6.6)$ \\
\hline$>85$ & 74 & 4 & $1.1(0.0,2.1)$ & 67 & $18.1(13.7,22.4)$ & 38 & $10.2(7.0,13.5)$ & 29 & $7.8(5.0,10.7)$ \\
\hline
\end{tabular}

${ }^{a}$ Modification of Diet in Renal Disease estimated glomerular filtration rate in $\mathrm{ml} / \mathrm{min}$ per $1.73 \mathrm{~m}^{2}$

any cause was six-fold more likely than progression to ESRD. Importantly, $61 \%$ of patients died, and only $5 \%$ of patients developed ESRD during a median follow-up of more than 9 years.

Prior studies in disparate settings have compared risks for ESRD versus death in patients with $\mathrm{CKD}$. The overall findings of our study are most similar to those from administrative data-based cohorts of CKD patients receiving care either in a Health Maintenance Organization (HMO) ${ }^{2}$ or in Veterans Affairs Medical Centers; ${ }^{19}$ both of these prior studies found older patients with moderate CKD were substantially more likely to die than to reach ESRD. However, in these studies, cause-specific death was not determined, and the mean followup time ranged from only 3 to 4 years for patients with moderate to severe CKD. On the opposite extreme from CHS are the findings of Menon et al. from the MDRD Study participants. ${ }^{20}$ Among 1,666 randomized and nonrandomized participants with predominantly stages 2 through 4 nondiabetic CKD, participants were seven-fold more likely to develop ESRD than to die prior to reaching ESRD. Even among participants more than 65 years of age, the rate of ESRD was double the rate of death. Differences between the MDRD cohort and CHS likely explain the differences in findings, including the younger age (mean age 50 years), the relatively low prevalence of CVD (8\%), the large proportion of participants with polycystic kidney disease (23\%), and the inclusion of patients selected for a RCT in the MDRD Study. Our CHS findings also differ from those of CKD patients referred for nephrologist care, who have been observed to have either higher or equal rates of ESRD as compared with rates of

Table 3. Risk Factors for Progression to ESRD and All-Cause Mortality Within the Competing Risk Framework

\begin{tabular}{|c|c|c|c|c|}
\hline & \multicolumn{2}{|l|}{ ESRD } & \multicolumn{2}{|l|}{ All-cause mortality } \\
\hline & $\mathrm{HR}(95 \% \mathrm{Cl})$ & p-value & $\mathrm{HR}(95 \% \mathrm{Cl})$ & p-value \\
\hline Age, per 5 year increase & $0.64(0.50,0.83)$ & $<0.001$ & $1.61(1.51,1.71)$ & $<0.001$ \\
\hline Male & $2.73(1.54,4.82)$ & $<0.001$ & $1.31(1.12,1.54)$ & $<0.001$ \\
\hline \multirow{2}{*}{\multicolumn{5}{|c|}{$\mathrm{BMI}^{a}$}} \\
\hline & & & & \\
\hline$<18.5$ & (No cases) & - & $2.37(1.37,4.10)$ & 0.002 \\
\hline $18.5-24.9$ & 1.00 (Ref) & & $1.00(\operatorname{Ref})$ & \\
\hline 25-29.9 & $2.38(1.14,5.00)$ & 0.021 & $0.98(0.83,1.16)$ & 0.821 \\
\hline$\geq 30$ & $2.45(1.11,5.41)$ & 0.027 & $0.88(0.70,1.11)$ & 0.282 \\
\hline Hypertension & $1.25(0.88,1.78)$ & 0.211 & $1.25(1.12,1.39)$ & $<0.001$ \\
\hline Diabetes mellitus & $1.74(0.95,3.19)$ & 0.072 & $1.57(1.29,1.92)$ & $<0.001$ \\
\hline Cardiovascular disease & $0.65(0.36,1.21)$ & 0.173 & $1.38(1.18,1.62)$ & $<0.001$ \\
\hline Heart failure & $1.05(0.46,2.40)$ & 0.798 & $1.77(1.33,2.35)$ & $<0.001$ \\
\hline \multicolumn{5}{|l|}{ Smoking status } \\
\hline Never & 1.00 (Ref) & & $1.00($ Ref) & \\
\hline Former & $0.48(0.26,0.91)$ & 0.024 & $1.36(1.16,1.61)$ & $<0.001$ \\
\hline Current & $0.53(0.21,1.33)$ & 0.175 & $2.25(1.75,2.90)$ & $<0.001$ \\
\hline $\mathrm{eGFR}^{b}$, per $10 \mathrm{ml} / \mathrm{min} / 1.73 \mathrm{~m}^{2}$ decrease & $3.25(2.53,4.18)$ & $<0.001$ & $1.04(0.95,1.13)$ & 0.460 \\
\hline \multicolumn{5}{|l|}{ Total cholesterol } \\
\hline$<200$ & 1.00 (Ref) & & 1.00 (Ref) & \\
\hline 200-239 & $0.86(0.45,1.64)$ & 0.650 & $0.90(0.76,1.06)$ & 0.199 \\
\hline$\geq 240$ & $1.59(0.84,3.01)$ & 0.156 & $0.94(0.76,1.16)$ & 0.558 \\
\hline
\end{tabular}

${ }^{a}$ Body mass index, ${ }^{b}$ Modification of Diet in Renal Disease estimated glomerular filtration rate 
death. ${ }^{21,22}$ However, referred patients may differ from nonreferred patients in important ways including their perceived health status and dialysis candidacy. ${ }^{23}$ Our findings allow clinicians to understand more generally the competing risks of death and ESRD in their older patients with CKD and expand on the previous findings as we determined the specific rates of competing events and compared risk factors for both ESRD and all-cause mortality within a competing risk framework. In our study, the rate of $\mathrm{CV}$ related death approached the rate of all other causes of death combined. Although we did not specifically examine the different types of non-CV-related death, a previous CHS study by Fried et al. $^{7}$ found that among participants with $\mathrm{CKD}$, the leading cause of non-CV death was cancer, and the rate of cancer-related deaths was lower than the rate of CV deaths (16.7 versus 28 per 1000 person-years).

In the competing risk framework, lower eGFR, male gender, African-American race, and higher BMI were associated with an increased risk of progression to ESRD. Bidirectional effects of age, tobacco use, and BMI were observed. Older age and former tobacco use were associated with a reduced risk of progression to ESRD and an increased risk of death, whereas current tobacco use was associated with a substantial increase in the risk of death, suggesting that age and tobacco use were stronger predictors of death than ESRD (i.e., a risk factor for renal function decline, such as tobacco, was in fact a much stronger predictor of death in the competing risk framework). Higher BMI was associated with an increased risk of progression to ESRD but not death, whereas a low BMI was associated with a significant increase in the risk of death (similar to findings from previous CHS studies ${ }^{24,25}$ ). Although diabetes and hypertension were not statistically significantly associated with an increased risk of ESRD, the point estimates were consistent with an increased risk of ESRD and were likely not statistically significant because of the low number of patients reaching ESRD.

Interestingly, renal function was an important predictor of ESRD but not all-cause mortality. Older age, cardiovascular disease, heart failure, and current tobacco use, all of which were more prevalent among participants with lower eGFR, appeared to have a greater influence on the likelihood of death as compared to progression to ESRD. In contrast, the comparative risk of diabetes or hypertension on these outcomes was less clear due to the overall similar effect sizes and the small number of participants reaching ESRD. Our findings suggest that older age, cardiovascular disease, heart failure, and current tobacco use enhance the risk of death, presumably through multiple mechanisms including an increase in cardiovascular events, cancer, and infection, resulting in death prior to progression of renal disease.

The strengths of our study include the methods used to ascertain ESRD, the adjudication of CV death, the long-term follow-up, and the implementation of the competing risk framework for our statistical analysis. In our study, we determined progression to ESRD through linkage to the USRDS and chart review. We detected $17 \%$ of our ESRD patients through chart review, underscoring the high degree of under-ascertainment when only relying on the USRDS to identify cases in this population. The use of sources other than the USRDS to identify ESRD may be even more important in older patients, a subgroup that may be more likely to have dialysis withheld or withdrawn. ${ }^{23}$ Importantly, we used the CHS adjudicated cause of death, which allowed us, in combination with findings from previous CHS studies, to establish $\mathrm{CV}$ death as the leading cause of death in older patients with CKD. In addition, we examined risk factors for ESRD while accounting for the competing risk of death. This statistical approach allowed us to understand risk factors for progression to ESRD as compared to death. Alternative approaches, such as censoring for death or combining ESRD and death as the outcome of interest, would not have allowed us to detect the bi-directional effects of age, BMI, and tobacco use.

Our study had several limitations. One, the findings are primarily applicable to community-dwelling older persons with moderate CKD, and the outcomes may be significantly different in institutionalized older persons. Second, we relied on a single creatinine measurement to estimate the MDRD eGFR, which may have resulted in misclassification of subjects at study entry (with patients most likely being misclassified as having CKD when they did not). However, this type of misclassification would likely result in an underestimate of events as opposed to an overestimate of events (i.e., healthier subjects without CKD would have been inaccurately classified as having CKD and would likely not contribute events but would erroneously be included in the CKD population). In addition, we did not have baseline measures of urinary protein and therefore we could not determine the effect of proteinuria on the risk of renal progression or death. The majority of participants included in our study had stage $3 \mathrm{a}$ CKD $(78 \%)$, and few participants had advanced CKD. Therefore, our study did not include a large number of participants at highest risk for progression to ESRD, and our findings primarily apply to patients with stage 3a CKD. Finally, because only $5 \%$ of the cohort progressed to ESRD, our ability to contrast the relative impact of a predictor on the risk of ESRD as compared to death is limited. Nonetheless, our cohort reflects the clinical course of moderate $\mathrm{CKD}$ in older community-dwelling persons and does identify important predictors of ESRD as compared with all-cause mortality.

In summary, we found that older patients with moderate CKD are substantially more likely to die than to reach ESRD, and $\mathrm{CV}$ death is the single leading cause of death in this population. These findings can aid clinicians in caring for and counseling their older patients with $\mathrm{CKD}$, and highlight the importance of cardiovascular risk reduction and screening for cardiovascular disease in this population.

Funding Source: The research reported in this article was supported by contract numbers NO1-HC-85079 through NO1-HC85086, NO1-HC-35129, NO1 HC-15103, NO1 HC-55222, NO1-HC75150, NO1-HC-45133, grant no. U01 HL080295 from the National Heart, Lung, and Blood Institute, with additional contributions from the National Institute of Neurological Disorders and Stroke, and by grant no. 0455628U from the American Heart Association, Grant Numbers R01AG027002 and R01 AG023629 from the National Institutes on Aging and grant no. UL1 RRO24146 from the National Center for Research for Medical Research. The funding bodies had no role in the design and conduct of the study; in the collection, management, analysis, and interpretation of the data; or in the preparation, review, or approval of the manuscript. A full list of participating CHS investigators and institutions can be found at http://www.chs-nhlbi.org. The contents are solely the responsibility of the authors and do not necessarily represent the official view of NCRR or NIH. 
Prior Presentation: The findings from this study were presented at the American Society of Nephrology Annual Meeting in San Diego, CA, on October 29, 2009 in a Poster Presentation.

Conflict of Interest Statement: Drs. Dalrymple, Katz, Shlipak, Seliger, Siscovick, and Newman report no conflicts of interest. Dr. Kestenbaum has received honoraria from Shire, Abbott, and Genzyme Inc., and has received grant funding from Amgen Inc. Dr. Sarnak has received funding from Tap Pharmaceuticals. Dr. Stehman-Breen is an employee of Amgen. Dr. Fried has provided expert testimony for Bayer and received a grant from Merck.

Open Access: This article is distributed under the terms of the Creative Commons Attribution Noncommercial License which permits any noncommercial use, distribution, and reproduction in any medium, provided the original author(s) and source are credited.

Corresponding Author: Lorien S. Dalrymple, MD, MPH; Department of Medicine, University of California Davis, 4150 V Street, \#3500 PSSB, Sacramento, CA 95817, USA (e-mail: lorien.dalrymple@ucdmc. ucdavis.edu).

\section{REFERENCES}

1. Lesley AS, Suying L, Changchun w, et al. Prevalence of CKD and comorbid illness in elderly patients in the United States: Results from the Kidney Early Evaluation Program (KEEP). Am J Kidney Dis. 2010;55(3): S23-S33.

2. Keith DS, Nichols GA, Gullion CM, Brown JB, Smith DH. Longitudinal follow-up and outcomes among a population with chronic kidney disease in a large managed care organization. Arch Intern Med. 2004;164 (6):659-63.

3. Peralta CA, Shlipak MG, Fan D, et al. Risks for end-stage renal disease, cardiovascular events, and death in Hispanic versus non-Hispanic white adults with chronic kidney disease. J Am Soc Nephrol. 2006;17 (10):2892-9.

4. Foley RN, Murray AM, Li S, et al. Chronic kidney disease and the risk for cardiovascular disease, renal replacement, and death in the United States Medicare population, 1998 to 1999. J Am Soc Nephrol. 2005; 16 (2):489-95.

5. Wan H, Sengupta M, Velkoff VA, and DeBarros KA. US Census Bureau, Current Population Reports, 65+ in the United States: 2005, US Government Printing Office, Washington, DC, 2005.23-209.

6. Coresh J, Selvin E, Stevens LA, et al. Prevalence of chronic kidney disease in the United States. JAMA. 2007;298(17):2038-2047.

7. Fried LF, Katz R, Sarnak MJ, et al. Kidney function as a predictor of noncardiovascular mortality. J Am Soc Nephrol. 2005;16(12):37283735 .
8. Go AS, Chertow GM, Fan D, McCulloch CE, Hsu CY. Chronic kidney disease and the risks of death, cardiovascular events, and hospitalization. N Engl J Med. 2004;351(13):1296-305.

9. Shlipak MG, Sarnak MJ, Katz R, et al. Cystatin C and the risk of death and cardiovascular events among elderly persons. $N$ Engl $\mathrm{J}$ Med. 2005;352(20):2049-60.

10. Fried LP, Borhani NO, Enright P, et al. The Cardiovascular Health Study: design and rationale. Ann Epidemiol. 1991;1(3):263-76.

11. Tell GS, Fried LP, Hermanson B, Manolio TA, Newman AB, Borhani NO. Recruitment of adults 65 years and older as participants in the Cardiovascular Health Study. Ann Epidemiol. 1993;3(4):358-66.

12. Ives DG, Fitzpatrick AL, Bild DE, et al. Surveillance and ascertainment of cardiovascular events: The Cardiovascular Health Study. Ann Epidemiol. 1995;5(4):278-285.

13. Psaty BM, Kuller LH, Bild D, et al. Methods of assessing prevalent cardiovascular disease in the Cardiovascular Health Study. Ann Epidemiol. 1995;5(4):270-277.

14. Ives DG. Agreement Between Nosologist and Cardiovascular Health Study Review of Deaths: Implications of Coding Differences. J Am Geriatri Soc. 2009;57(1):133-139.

15. Cushman M, Cornell ES, Howard PR, Bovill EG, Tracy RP. Laboratory methods and quality assurance in the Cardiovascular Health Study. Clin Chem. 1995;41(2):264-70.

16. Weiner DE, Tighiouart H, Amin MG, et al. Chronic kidney disease as a risk factor for cardiovascular disease and all-cause mortality: a pooled analysis of community-based studies. J Am Soc Nephrol. 2004;15(5): 1307-1315.

17. National Kidney Foundation, Inc. Part 5. Evaluation of laboratory measurements for clinical assessment of kidney disease. Am J Kidney Dis. 2002;39(2):S76-S110.

18. Fine JP, Gray RJ. A Proportional hazards model for the subdistribution of a competing risk. J Am Stat Assoc. 1999;94(446):496-509.

19. O'Hare AM, Choi AI, Bertenthal D, et al. Age affects outcomes in chronic kidney disease. J Am Soc Nephrol. 2007;18(10):2758-2765.

20. Menon V, Wang X, Sarnak MJ, et al. Long-term outcomes in nondiabetic chronic kidney disease. Kidney Int. 2008;73(11):1310-5.

21. Levin A, Djurdjev O, Beaulieu M, Er L. Variability and risk factors for kidney disease progression and death following attainment of stage 4 CKD in a referred cohort. Am J Kidney Dis. 2008;52(4):661-71.

22. Agarwal R, Bunaye Z, Bekele DM, Light RP. Competing risk factor analysis of end-stage renal disease and mortality in chronic kidney disease. Am J Nephrol. 2008;28(4):569-75.

23. Sekkarie MA, Moss AH. Withholding and withdrawing dialysis: The role of physician specialty and education and patient functional status. Am J Kidney Dis. 1998;31(3):464-472.

24. Diehr P, Bild DE, Harris TB, Duxbury A, Siscovick D, Rossi M. Body mass index and mortality in nonsmoking older adults: the Cardiovascular Health Study. Am J Public Health. 1998;88(4):623-629.

25. Fried LP, Kronmal RA, Newman AB, et al. Risk factors for 5-year mortality in older adults: the Cardiovascular Health Study. JAMA. 1998;279(8):585-92. 